\title{
Ovarian Biphasic or Triphasic Teratoma
}

National Cancer Institute

\section{Source}

National Cancer Institute. Ovarian Biphasic or Triphasic Teratoma. NCI Thesaurus. Code C39992.

A germ cell tumor that arises from the ovary and is composed of tissues that originate from two or three of the following germ layers, endoderm, ectoderm, or mesoderm. 